\title{
Wide Range RH Detection with Digital Readout: Niche Superiority in Terms of Its Exceptional Performance and Inexpensive Technology
}

\author{
Manju Pandey, Kusum Sharma, Saikh Safiul Islam* \\ Centre for Nanoscience and Nanotechnology, Jamia Millia Islamia, New Delhi, India \\ Email: *sislam@jmi.ac.in
}

How to cite this paper: Pandey, M., Sharma, K. and Islam, S.S. (2019) Wide Range RH Detection with Digital Readout: Niche Superiority in Terms of Its Exceptional Performance and Inexpensive Technology. Advances in Materials Physics and Chemistry, 9, 11-24.

https://doi.org/10.4236/ampc.2019.92002

Received: January 14, 2019

Accepted: February 24, 2019

Published: February 27, 2019

Copyright $\odot 2019$ by author(s) and Scientific Research Publishing Inc. This work is licensed under the Creative Commons Attribution International License (CC BY 4.0).

http://creativecommons.org/licenses/by/4.0/

\begin{abstract}
In this paper we report alumina based capacitive humidity sensor having exceptional sensing performance in wide range RH segment (10\% - 90\%). The developed sensor has an improvement of accuracy, reliability, and economic efficiency; apart from fast response and recovery time $(\sim s)$, negligible baseline drift and high selectivity for moisture. The sensing mechanism was discussed based on their microstructures, such as surface area and mesopore volume. In general, at low humidity, surface area and water adsorption play the dominant role, while at high humidity, mesopore volume and capillary condensation become important. Standard characterization techniques such as AFM, FESEM, BET, XRD and impedance spectroscopy were employed for micro-structural and electrical characterization of RH sensor. The nano porous alumina film undergoes a huge change in dielectric upon adsorption of moisture, ensuing large change in capacitance. Additionally, a prototype $\mathrm{RH}$ meter has been developed with digital readout for humidity. The interface circuit was based on capacitor-to-duty cycle (CDC) converter. The proposed digital circuit has the advantage of performing adaptive measurements as a function of resolution and bandwidth. The prototype instrument can be used for sub ppm level moisture detection where stability and response are completely unaffected even in highly toxic ambience viz. $4 \%$ ammonia and $4 \%$ chlorine.
\end{abstract}

\section{Keywords}

Ceramics, Sol-Gel, Nanoporous, Sensor, Toxic Gases

\section{Introduction}

Humidity sensing studies have progressed rapidly and humidity sen- 
sors-regardless of fabrication technique-have been widely employed in large number of applications including process control and automation, pharmaceutical and R \& D industry, food grain storage and notably for diagnosis and early detection of various diseases like COPD, asthma and cancer etc. [1] [2] [3] [4]. There are several groups working in collaboration with industries to fulfill the rigid demands of the present day applications [1] [2] [3] [4]. Cylinders having oxygen, nitrogen and even toxic gases either used for healthcare and crucial $\mathrm{R} \&$ $\mathrm{D}$ purpose, are generally supplied as a pure and uncontaminated product. The presence of water vapor is the most undesirable and is a quality imperfection [5] [6] [7] [8] [9]. Even in hazardous toxic gas industrial environment, the monitoring of humidity level is required for specific needs. Therefore, there is critical requirement to design and devise a sensor which can work in these specific areas. Polymer based humidity sensors are quite popular among researchers [10]. However, there are many characteristic problems associated with humidity sensors based on polymers such as hydrophilic nature, thus dissolves in water, narrow temperature range $\left(-10^{\circ} \mathrm{C}\right.$ to $\left.80^{\circ} \mathrm{C}\right)$, inaccurate at low humidity $(<15 \%$ $\mathrm{RH})$ and requires frequent calibration [11].

Even alumina-based humidity sensors suffer a major drawback, i.e., long-term calibration drift [12]. The basic reason for such is due to structural change of alumina from $\gamma$-to $\alpha$-phase when exposed to humid environment [13] and it is irreversible. This causes volume expansion of aluminium oxide, resulting in the gradual decrease of surface area and porosity [14]. Efforts are on for complete elimination of this drift [13]. Even the commercial aluminium oxide moisture sensors have to be calibrated twice a year to assure their accuracy [13]. This problem seriously hinders the widespread use of aluminum oxide moisture sensors.

In this report, the developed ceramic based humidity sensor is insoluble in water, operational over wide temperature range $\left(-40^{\circ} \mathrm{C}\right.$ to $\left.150^{\circ} \mathrm{C}\right)$, corrosion-resistant, wide sensing range, highly accurate and selective for moisture only. The ceramic is prepared by Sol-gel route compared to other synthesis techniques; the process is simple, low cost, with precise control over composition [11] [12] [13] [14]. The exceptional sensing performance includes its stability and long term drift. The sensor has for two consecutive years and no significant drift observed. The developed RH humidity sensor can work for wide application range including toxic gases like ammonia and chlorine of high concentrated level. The digital design and realization of the prototype RH meter for the measurement of humidity in the range of $10 \% \mathrm{RH}$ to $90 \% \mathrm{RH}$ is also presented with the advantage of performing adaptive measurements with resolution and bandwidth. The power consumption is kept low by using small number of components with simple design of the interfacing circuit. The execution of a model readout circuit worked with a $1 \mathrm{KHz}$ bandwidth.

\section{Experimental}

\section{1) Preparation of alumina sol solution}


Aluminium-sec-butoxide is the starting material used for preparing alumina sol [15] [16] [17]. This organo-metallic compound is hydrolysed in 1:100 molar ratios at elevated temperatures $\left(80^{\circ} \mathrm{C}-90^{\circ} \mathrm{C}\right)$. The prepared solution was peptized with hydrochloric acid. Peptization was done to ionise the suspended nanoparticles. The particles repel each other ensuing coagulation free sol formation. This process also turned the milky appearance of the solution into transparent colloidal suspension, indicating stable sol formation. In order to make sheet from the prepared sol, $2 \mathrm{wt} \%$ of binder i.e. Poly vinyl alcohol (PVA) is added. The solution was then rigorously stirred for 2 hour at $90^{\circ} \mathrm{C}$ making it more viscous. The prepared colloidal suspension is kept bubble free to avoid the development of cracks in the film.

\section{2) Fabrication of capacitive humidity sensor}

Figure 1 shows the fabrication steps for preparing capacitive humidity sensor. The alumina substrate of dimension $(20 \mathrm{~mm} \times 20 \mathrm{~mm} \times 1 \mathrm{~mm})$ was used as substrate. A thin film of alumina was deposited over the gold coated substrate using dip coating method. The withdrawal speed was $60 \mathrm{~mm} / \mathrm{min}$ followed by drying at $80^{\circ} \mathrm{C}$ after each coating.

The film was calcined at $450^{\circ} \mathrm{C}$ for 5 hours at $100^{\circ} \mathrm{C} /$ hour rate, for achieving stable $\gamma$-phase of alumina. Second electrode was prepared by screen printing method. In order to obtain macro-porous gold film, the prepared electrode was dried at $900^{\circ} \mathrm{C}$ as shown in Figure 1 (b). In the present work, the capacitive sensor based on gold coated alumina substrate (act as electrode) on which porous alumina thin film was deposited through Sol-gel technique. To prepare another electrode, porous alumina thin film was covered by gold by screen printing method. Electrical connections were taken out from the aforementioned parallel electrodes. The film grown on the gold coated substrate was used as transducing layer for humidity sensing. The dielectric of the porous layer changes, when moisture diffuses into the inner pore regions and absorbs on the sensing porous layer. The water vapour was diffuse through the permeable porous electrodes to the sensing layer i.e. alumina film and hence increase in capacitance is observed.

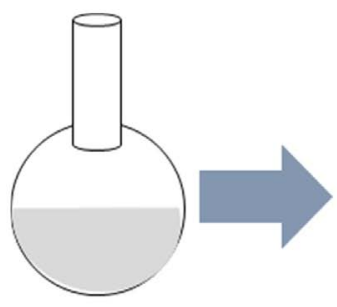

(a)

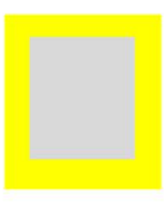

(b)

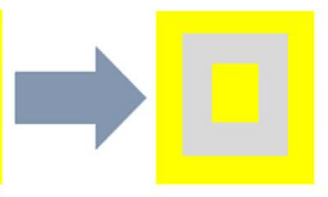

(c)

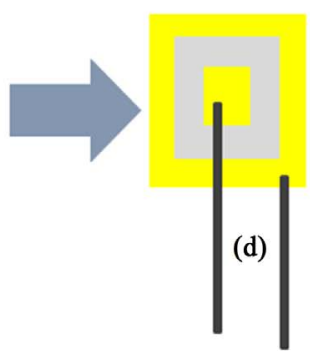

Figure 1. Flow diagram for developing humidity sensor. (a) Alumina Sol; (b) Formation of film over gold coated substrate; (c) Formation of second electrode by screen printing; (d) Electrode curing; (e) Sensor. 


\section{Results \& Discussion}

\section{1) Zeta potential measurement}

Zeta potential [18] is an important characterization tool that is related to nanoparticle stability or aggregation in dispersion. The zeta potential of the prepared sol was $\pm 35 \mathrm{mV}$, indicating moderately stable sol formation.

Measurement was done at ambient conditions. In order to determine the surface chemistry of alumina film, electrostatic repulsion of the particles, in relation to the $\mathrm{pH}$ value of aqueous systems was analysed. Figure 2 shows the charging behaviour at the alumina-water interface with changing $\mathrm{pH}$ without adding binders. The isoelectric point of prepared alumina is 8 , which is characteristic feature of most metal oxide. The value indicates the concentration of nanoparticles and in good agreement with the literature [19] [20] [21] [22].

\section{2) Surface morphology\& pore size analysis}

Surface morphology is an important parameter to predict the sensor characteristics. The porosity and surface area analysis of sol-gel prepared alumina film was carried out by BET (Brunaur-Emmet-Teller) method.

Table 1 shows the surface area, pore size and porosity of the alumina film which is used as a sensing layer. Pore size distribution was measured by pore size analyser (NOVA 2000e) by BJH (Barrett-Joyner-Halenda) method, as shown in Figure 3.

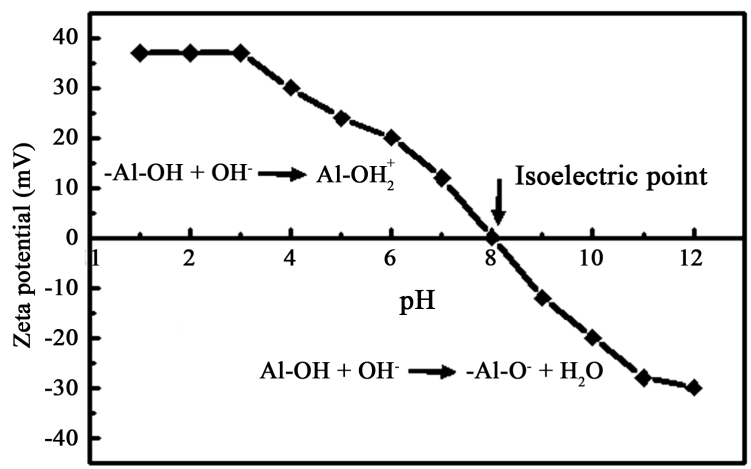

Figure 2. Zeta potential and surface charge behaviour of alumina sol.

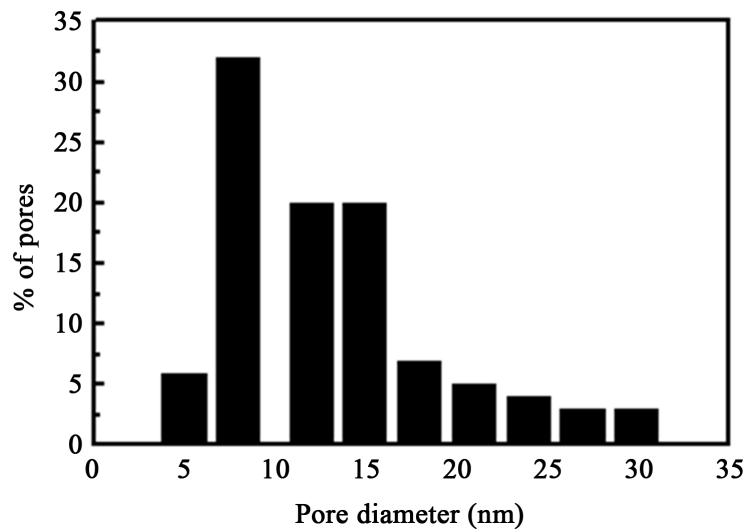

Figure 3. Pore size distribution of alumina film using BJH method. 
Table 1. Investigation of surface area, pore size and porosity present in $\gamma$-phase of alumina thin film by BET analysis.

\begin{tabular}{ccccc}
\hline Thin Film & $\begin{array}{c}\text { Heat Treatment } \\
\left({ }^{\circ} \mathrm{C}, \text { Hour }\right)\end{array}$ & $\begin{array}{c}\text { BET Surface Area } \\
\left(\mathrm{m}^{2} / \mathrm{g}\right)\end{array}$ & $\begin{array}{c}\text { Pore Diameter } \\
(\mathrm{nm})\end{array}$ & $\begin{array}{c}\text { Porosity } \\
(\%)\end{array}$ \\
\hline $\mathrm{Al}_{2} \mathrm{O}_{3}$ & $450,5 \mathrm{~h}$ & 100.2 & 8.81 & 60 \\
\hline
\end{tabular}

The prepared sensor has high sensitivity owing to its nano pores $(\sim 9 \mathrm{~nm})$ and high porosity (60\%).

3) Phase determination of alumina ( $X$-ray diffraction studies)

$\mathrm{X}$-ray diffraction was carried out in order to determine the phases of synthesized alumina. PAN analytical X-ray Diffractometer (PW1830, Philips) with $\mathrm{Cu}-\mathrm{K} \alpha$ radiation $\left(\lambda=1.54 \AA \stackrel{\AA}{\mathrm{A}}\right.$; Range $\left.(2 \theta)=20^{\circ}-80^{\circ}\right)$ was used for the purpose.

Figure 4(a) shows the XRD of boehmite (PDF: 01-083-2384) [( $\mathrm{Al}(\mathrm{O}) \mathrm{OH})$ ] thin film. Boehmite was transformed to $\gamma-\mathrm{Al}_{2} \mathrm{O}_{3}$ upon calcined at $450^{\circ} \mathrm{C}$, according to following reaction:

$$
2 \mathrm{AlO}(\mathrm{OH}) \rightarrow \mathrm{Al}_{2} \mathrm{O}_{3}+\mathrm{H}_{2} \mathrm{O}
$$

All the peaks in Figure 4(b) corresponds to $\gamma$-phase of alumina (PDF: 00-029-0063) corresponds to the conversion of dehydroxylated boehmite to $\gamma-\mathrm{Al}_{2} \mathrm{O}_{3}$ via the intermediate formation of amorphous alumina. Boehmite $(\mathrm{AlO}(\mathrm{OH}))$ does not change to $\gamma-\mathrm{Al}_{2} \mathrm{O}_{3}$ directly. It first converts to an amorphous alumina on dehydroxylation which subsequently transforms to $\gamma-\mathrm{Al}_{2} \mathrm{O}_{3}$.

\section{4) Morphology of nano porous film}

Figure 5 shows the FESEM (FEI, Nova Nano SEM 450) micrographs of the sol-gel prepared nano porous alumina film. Figure 5(a) shows thin film deposited by the dip-coated method on gold coated alumina substrate. It demonstrates that the developed film is free of micro cracks. Figure 5(b) shows a calcined nano porous thin film where pores are uniformly distributed throughout the film and are responsible for high sensitivity for humidity. Figure 5(c) shows the thickness of the film after calcinations process. Figure 5(d) shows the top porous gold electrode through which humidity diffuse and reaches to sensing membrane.

The roughness of the nano porous film was verified by AFM (Solver Next, NT-MDT) measurements. The contact mode measurement was followed with the tip radius of $20 \mathrm{~nm}$. Roughness is a parameter which is of paramount importance in sensing applications. For large sensitivity, rough surfaces being preferred. It was determined by AFM image (Figure 6(c)) that $\gamma-\mathrm{Al}_{2} \mathrm{O}_{3}$ exhibited high roughness which was used as a sensing membrane in $\mathrm{RH}$ sensor.

\section{5) RH sensor-real time response}

The analysis of sensing parameters of the sol gel based sensor was determined by inserting the sensor in a stainless steel chamber. Different humidity concentration was achieved by mixing the carrier gas with humid gas. The mixing gas flow pressure was set to $2 \mathrm{bar} / 50 \mathrm{psi}$. Dielectric investigation was executed by semiconductor characterization system (4200 SCS, Keithley). A commercial 


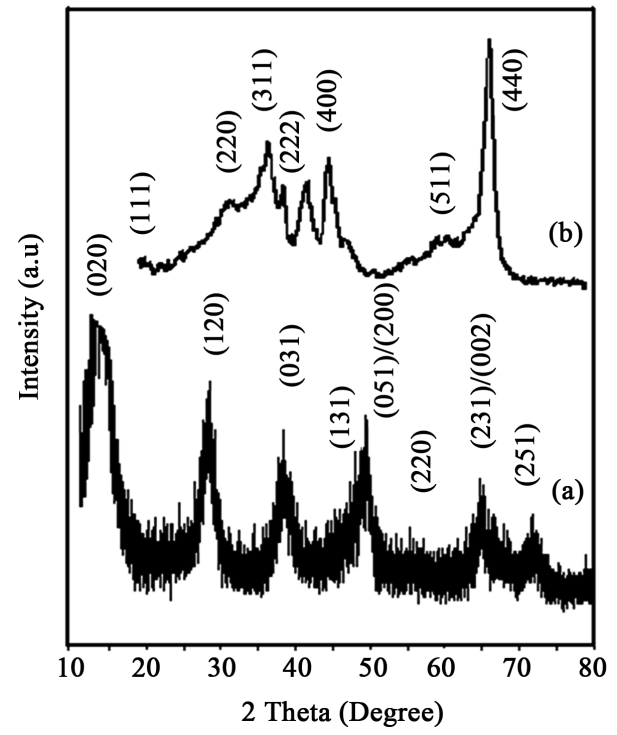

Figure 4. XRD micrographs of (a) boehmite $(\mathrm{AlO}(\mathrm{OH}))$; and (b) $\gamma-\mathrm{Al}_{2} \mathrm{O}_{3}$ phase of alumina film.
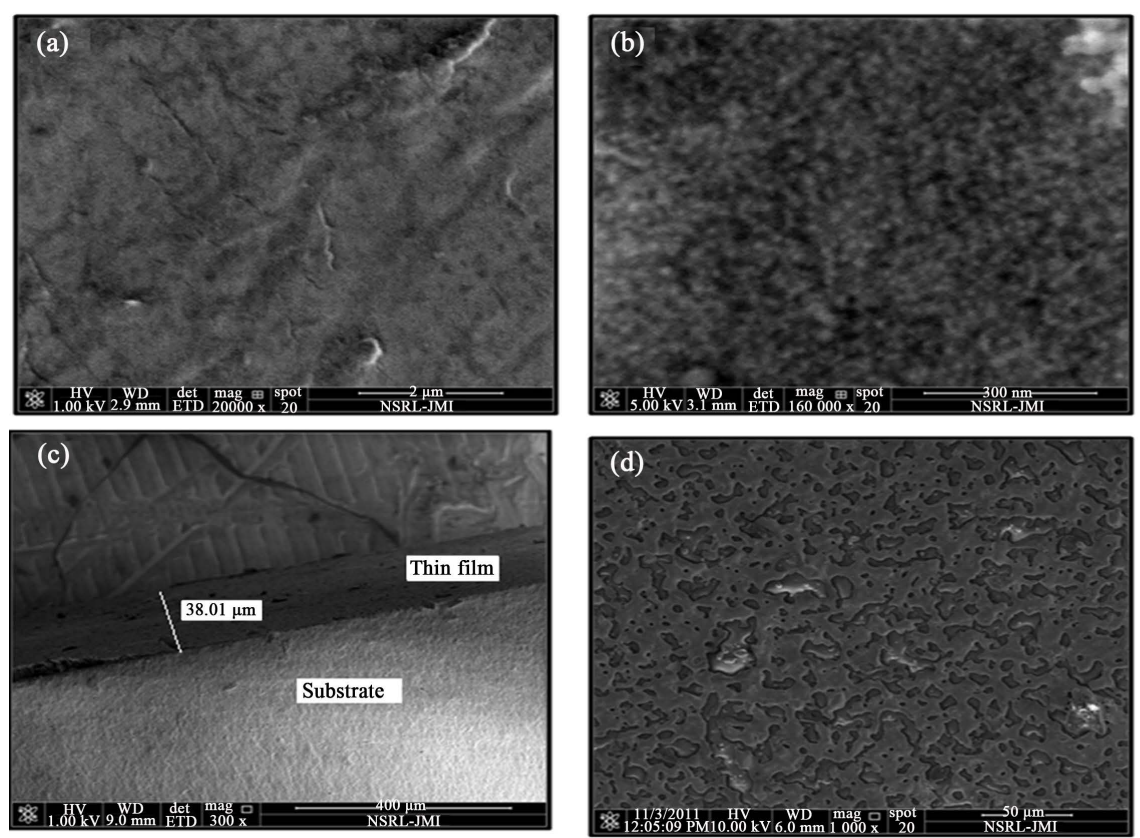

Figure 5. FESEM micrographs of (a) boehmite phase (dip-coated thin film at $80^{\circ} \mathrm{C}$ ); (b) $\gamma-\mathrm{Al}_{2} \mathrm{O}_{3}$ calcined thin film at $450^{\circ} \mathrm{C}$; (c) calcined film thickness; and (d) top porous gold electrode at $900^{\circ} \mathrm{C}$.

humidity sensor (SHAW) was used as a reference sensor to check the as prepared sensor performance. The measurement has been performed in the range $10 \%$ to $90 \% \mathrm{RH}$. The normalized capacitance change is $0.28 / \mathrm{RH} \%$.

Figure 7 shows the capacity versus humidity level (RH \%) plot at $1 \mathrm{KHz}$. The plot shows the linear dependence between $\mathrm{RH} \%$ and capacitance. Figure 8 shows the response and recovery time of $\mathrm{RH}$ sensor. It is shown that the sensor is exceptionally fast having response and recovery time, both less than $1 \mathrm{~s}$. The 


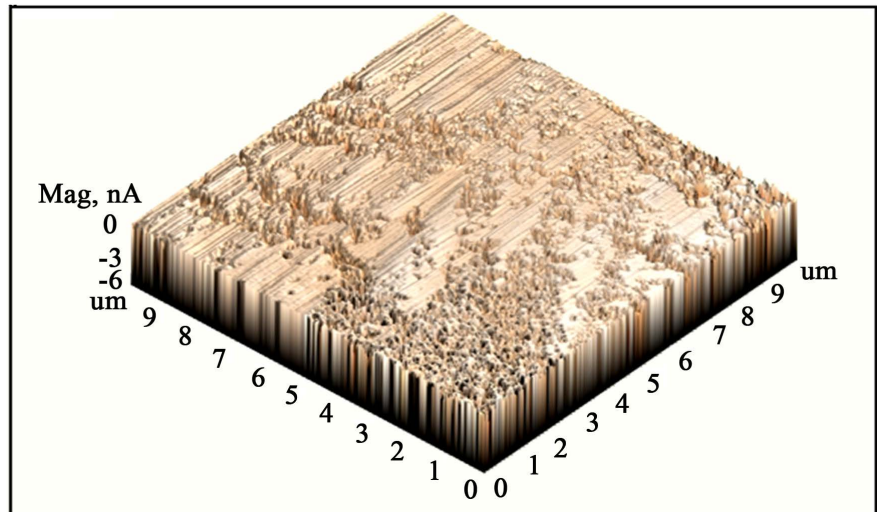

(a)

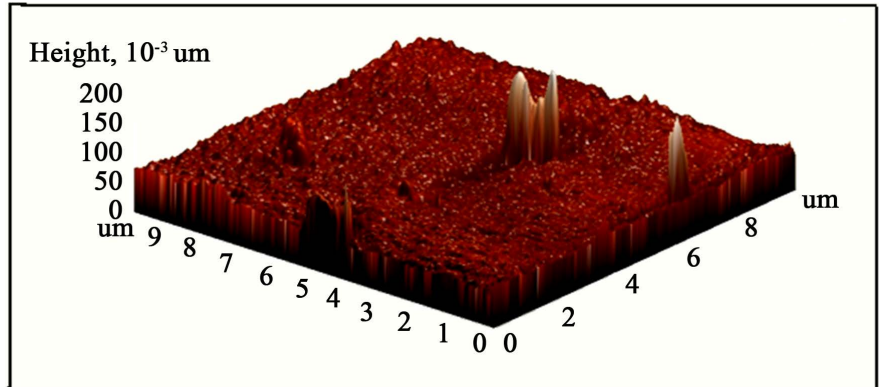

(b)

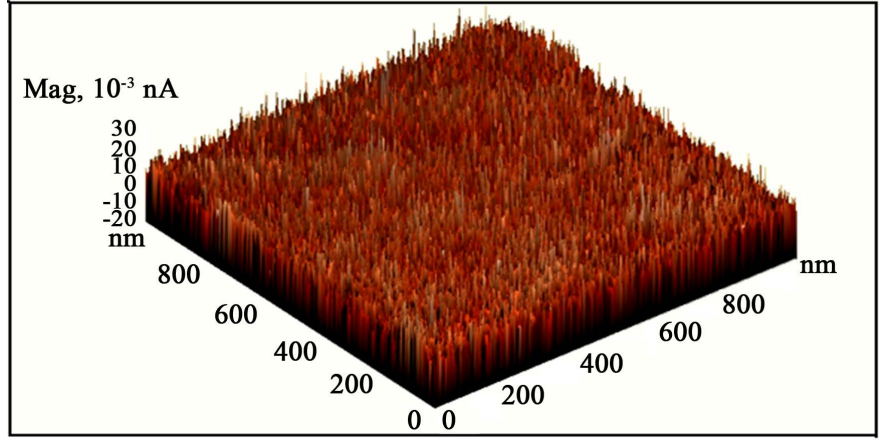

(c)

Figure 6. AFM image of (a) Alumina substrate; (b) Dip-coated thin film (Boehmite phase); (c) Thin film at $450^{\circ} \mathrm{C}$ or $\gamma-\mathrm{Al}_{2} \mathrm{O}_{3}$.

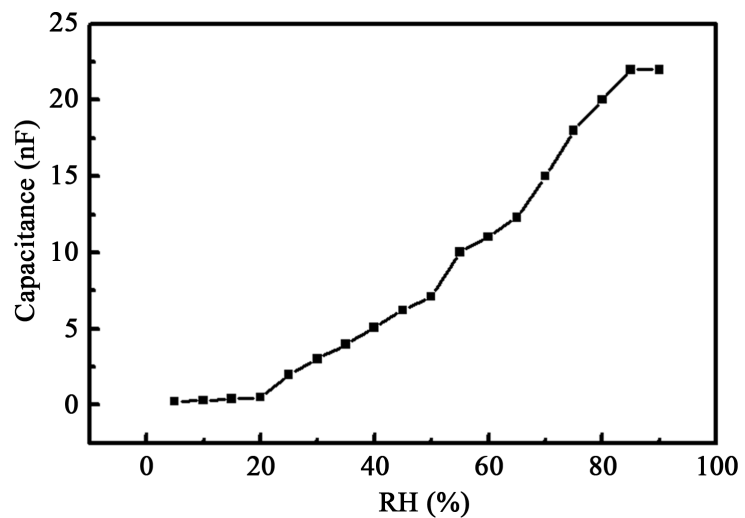

Figure 7. Capacitance versus humidity (RH \%) curve at $1 \mathrm{KHz}$. 


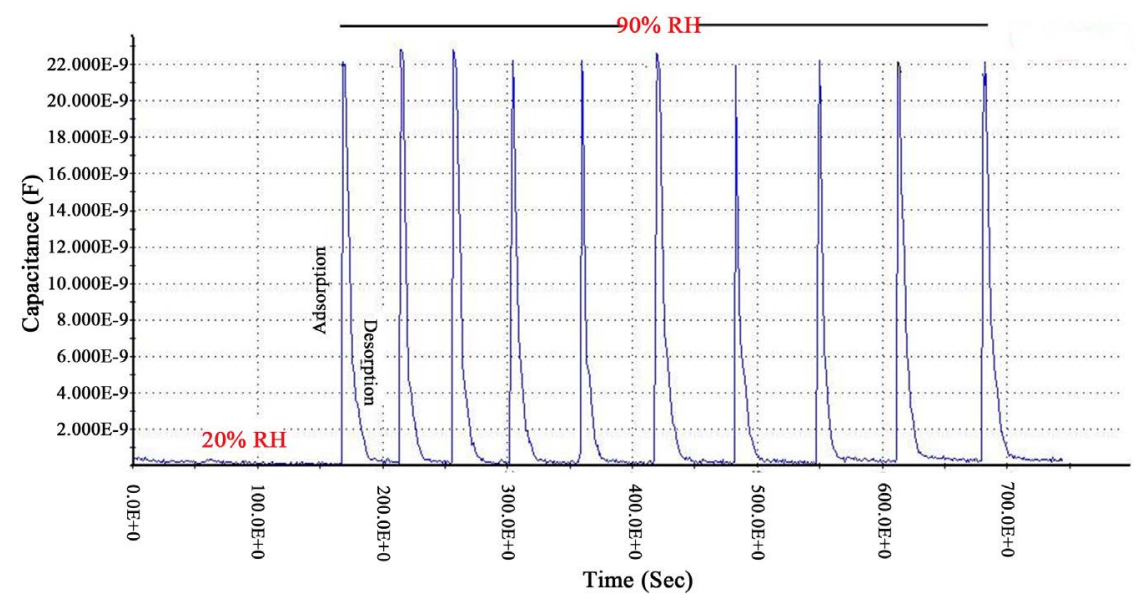

Figure 8. Response and recovery time of RH sensor.

transient curve (Figure 8) was taken for a number of cycles, ensuring good repeatability. To test its stability, it was exposed to different RH values for 12 hours and its sensing response remains unchanged (Figure 9). The sensors were repeatedly run for six months since its fabrication and found no significance long term drift (Figure 10).

6) Sensing mechanism

In the present work, a capacitive humidity sensor is fabricated where a hygroscopic dielectric material (alumina) is sandwiched between a pair of electrodes forming a capacitive structure. When the sensing layer is exposed to moisture; water permeates to it through top gold electrode. Initially, when humidity is low chemisorption takes place on the oxygen and metal ions on the surface as schematically shown in the Figure 11.

As humidity increases, more water molecules attached on the surface (physisorption) leading to the formation of hydroxyl ion and a proton. In physiosrption process, proton moved through the adsorbed water layer in accordance to the Grotthus mechanism [23].

At room temperature, dielectric constant of water vapour has a value of 80 ; which is exceptionally high compared to the dielectric constant of the porous alumina whose dielectric constant is 9.6. Thus, substantial increase in capacitance of a present sensor is attributed to remarkable change in the dielectric constant of hygroscopic alumina layer on adsorption of water vapour as observed for different humidity levels.

Figure 12 shows the orientation loss factor $\left(\varepsilon^{\prime \prime}\right)$ of adsorbed water vapour by the nano porous dielectric (alumina) film as a function of frequency for different RH viz. $10 \%$ RH, $20 \%$ RH, $30 \%$ RH, $40 \%$ RH, $50 \%$ RH, $60 \%$ RH, $70 \%$ RH, $80 \%$ $\mathrm{RH}$ and $90 \% \mathrm{RH}$. The imaginary component of permittivity $\varepsilon^{\prime \prime}$ describes the dipole relaxation phenomena and, bound charge which measures energy loss.

As evident from Figure 7, at low frequency (upto $2 \mathrm{KHz}$ ) orientation loss factor $\varepsilon^{\prime \prime}$ linearly with $\mathrm{RH}$ and above $2 \mathrm{KHz}$ orientation loss factor $\varepsilon$ " becomes independent of RH. This is explained as, when the sensor is excited by AC signal, 


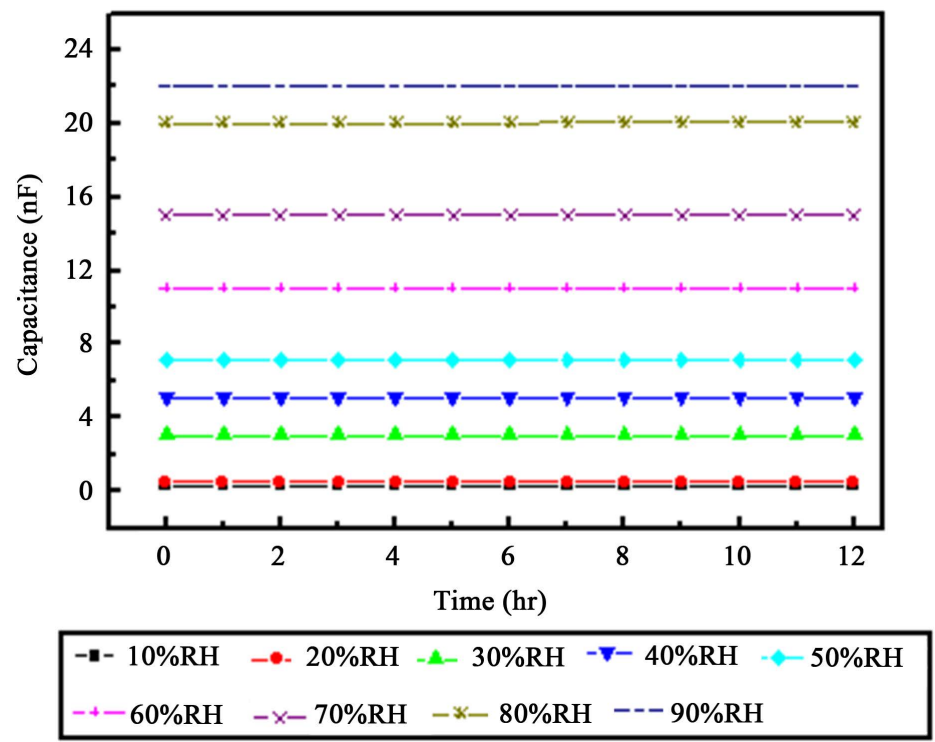

Figure 9. Short term stability curve of the RH sensor.

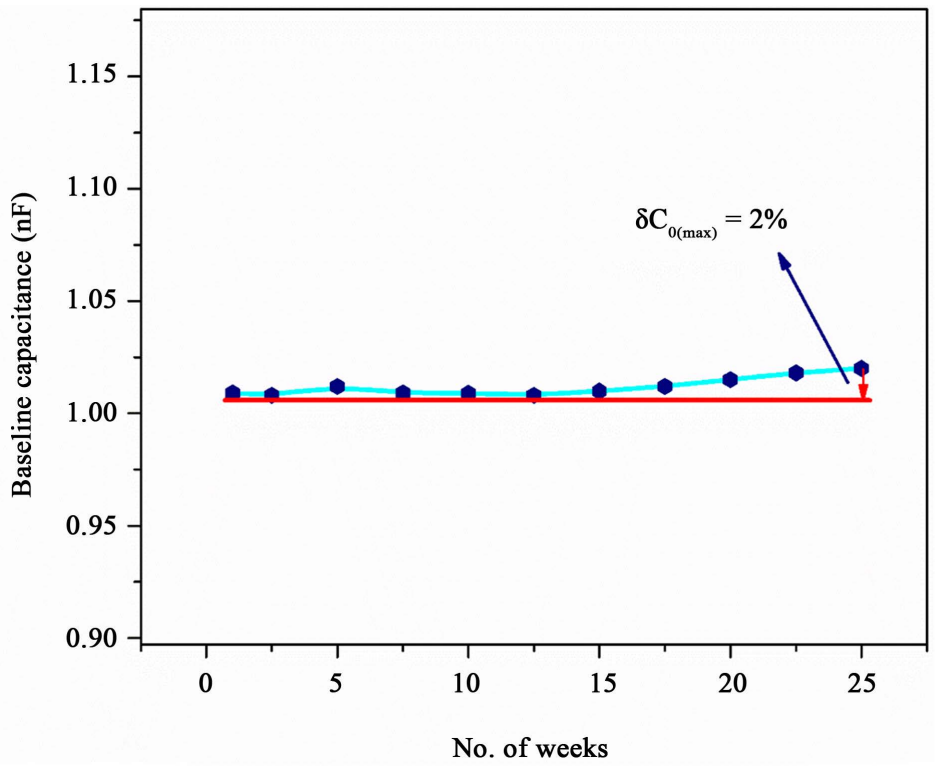

Figure 10. Long term stability curve of the RH sensor.

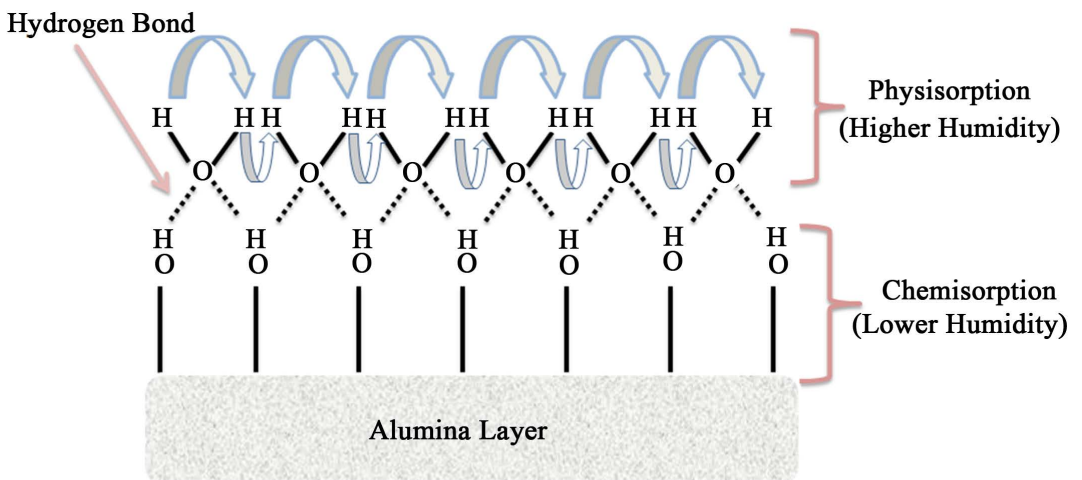

Figure 11. Schematic illustration of humidity sensing mechanism by alumina film. 


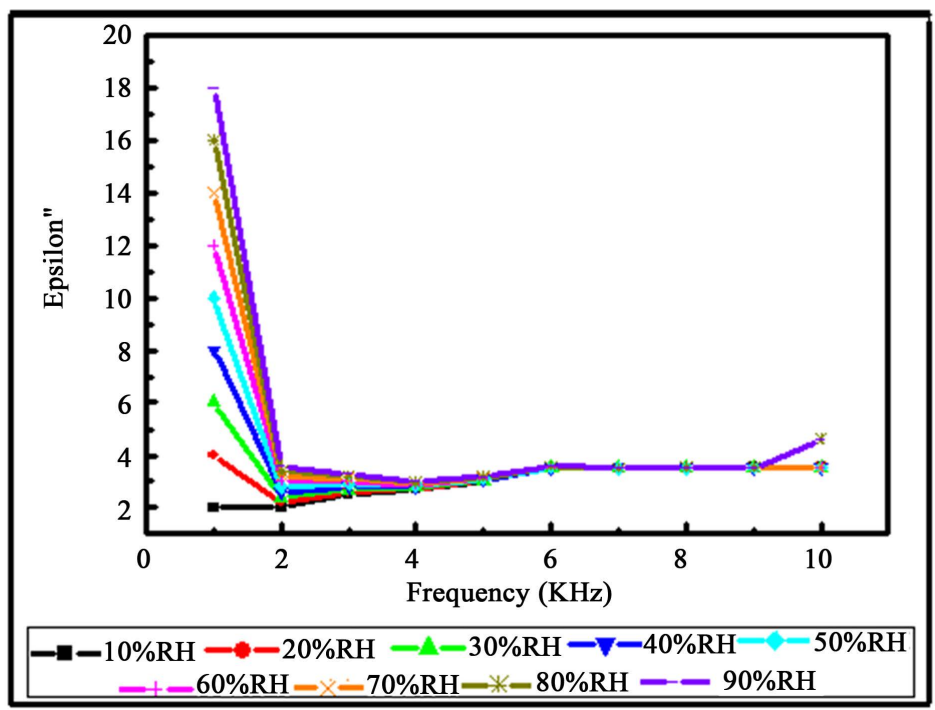

Figure 12. Complex permittivity versus frequency curve at different RH\% level.

the water molecule gets polarised and follows the changing electric field. However, at higher frequencies water molecules are not able to cope up with fast changing electric field [22] [23]. Hence, $\varepsilon^{\prime \prime}$ becomes independent of RH at higher frequencies $(>2 \mathrm{KHz})$.

7) $R H$ sensor response in toxic environment

The fabricated RH sensor was also examined for measurement of water content present in toxic gases such as ammonia and chlorine. Figure 13 shows the $\mathrm{RH}$ sensor's performance before and after it was exposed to toxic gases and inset displays the working ambience ( $4 \%$ ammonia, $4 \%$ chlorine, and $92 \%$ moisture).

The change in capacitance w.r.t RH\% remains constant, and it indicates that the sensitivity of the sensor was not affected by exposing to toxic gases. From Table 2, we observed that most of the commercially available sensor has no data for response in toxic environment [24] [25] [26] [27].

It is the advantage of developed $\mathrm{RH}$ sensor, that it can be used by different industries where a constant humidity monitoring is required in the presence of toxic gases, without affecting the sensing property of sensor. The reason behind that alumina has high affinity for water.

\section{8) Interfacing circuit for digital readout}

To develop a prototype of the capacitive RH sensor, generally, the interfacing circuits, includes capacitance-to-voltage, capacitance-to-frequency [28], and capacitance-to-phase conversion. The interfacing circuit we used specifically converts capacitance into a digital readout. The depicted circuit was sensitive and free from drift and noise.

The working of the circuit is based upon change in capacitance of the sensing component being transformed into a variable duty cycle repetitive pulse signal. A digital counter triggered by the start and end of the pulse "on" phase monitors the variable duty cycle of a signal and converts the pulse duration into a digital number. 
Figure 14 shows the interfacing circuit. LM311 was employed as a comparator. LF353operational amplifier was utilized for the feedback amplifier and voltage follower. A "basic stamp" PIC16C57 microprocessor with a BS2-IC module was utilized to govern the counter and timing of the analog part. Figure 15 shows the comparator output and sampling clock of the CDC conversion circuit.

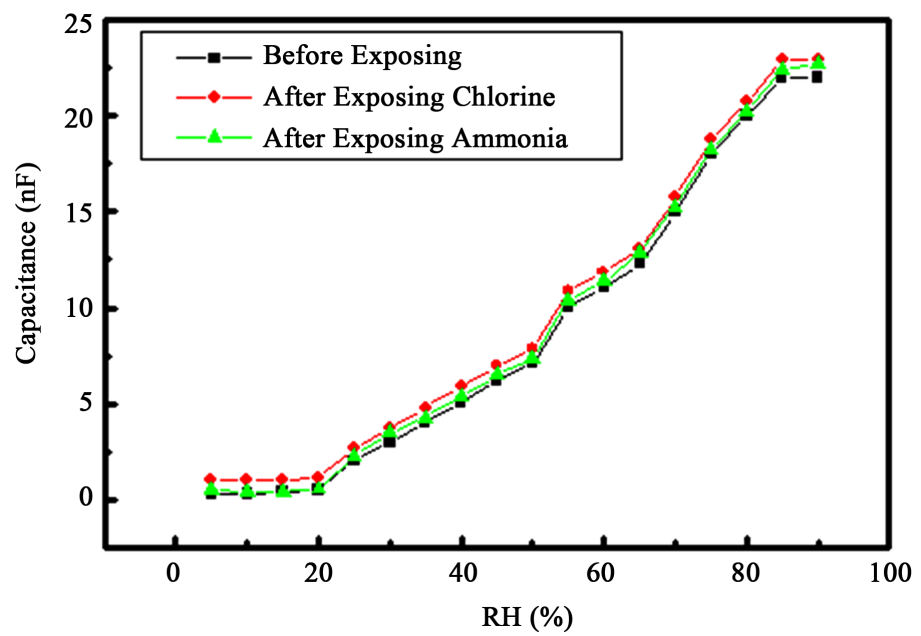

Figure 13. Capacitive response of RH sensor before and after exposure to toxic gases (ammonia and chlorine).

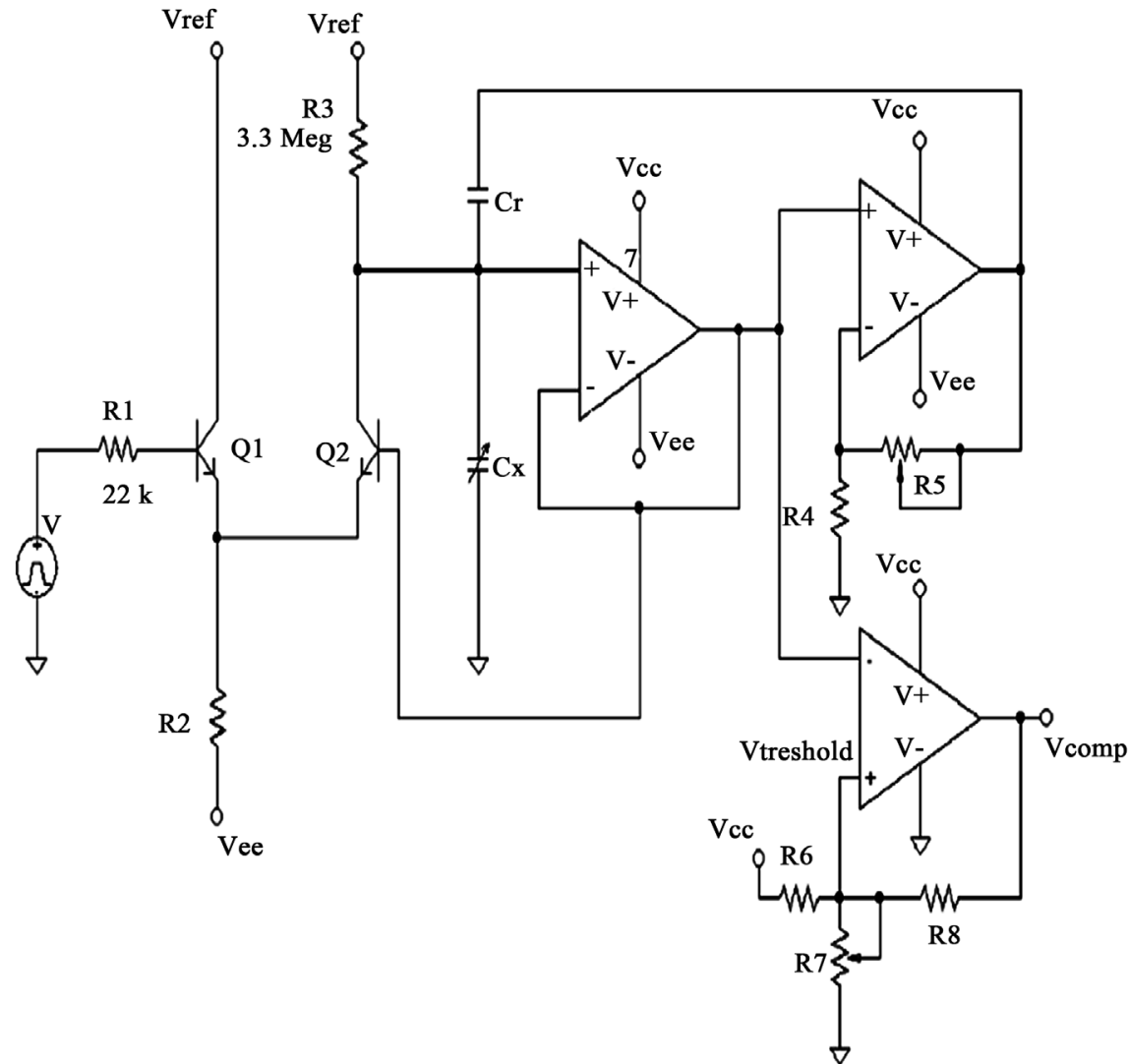

Figure 14. Schematic diagram of the CDC conversion circuit. 


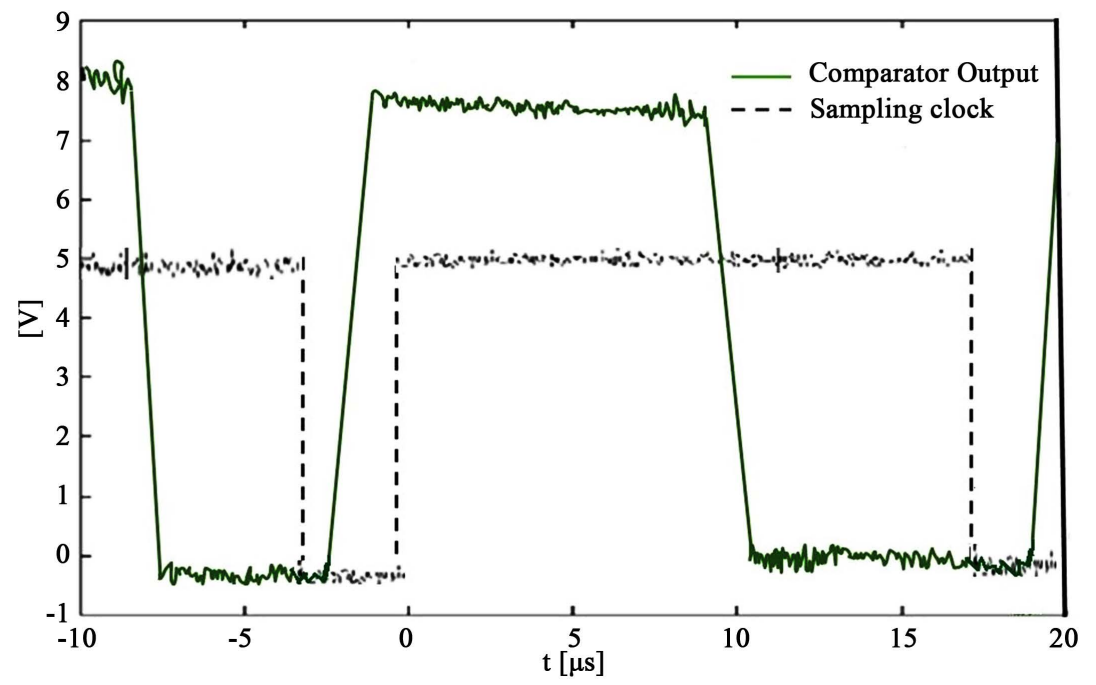

Figure 15. Comparator output and sampling clock of the CDC conversion circuit.

Table 2. Toxic resistant behavior of commercially available sensors.

\begin{tabular}{cccccc}
\hline S. No. & Sensor & $\begin{array}{c}\text { Moisture Measurement } \\
\text { in Toxic Environment }\end{array}$ & Approx. Cost & Technology Used & Reference \\
\hline 1. & Shaw & $\mathrm{NM}^{*}$ & $\sim 3000 \$$ & $\begin{array}{c}\text { Aluminium Oxide } \\
\text { Capacitive sensor }\end{array}$ & 25 \\
2. & GE & $\mathrm{NM}^{*}$ & $\sim 1000 \$$ & $\begin{array}{c}\text { Thin film } \\
\text { Aluminium Oxide }\end{array}$ & 26 \\
3. & Vaisala & $\begin{array}{c}\text { Insensitive to dust } \\
\text { \& most chemical }\end{array}$ & $\sim 861 \$$ & $\begin{array}{c}\text { Thin film } \\
\text { polymer sensor }\end{array}$ & 27 \\
4 & Tiger & $\begin{array}{c}\text { Measure moisture } \\
\text { in toxic gases }\end{array}$ & $\sim 60,000 \$$ & $\begin{array}{c}\text { Cavity Ring Down } \\
\text { Spectroscopy }\end{array}$ & 28 \\
\hline
\end{tabular}

\section{Conclusion}

We have developed sol-gel based $\mathrm{RH}$ sensor that works in very low to high $\mathrm{RH}$ level i.e. $10 \%$ to $90 \%$ with exceptional efficiency. It has high stability, good accuracy, sensitivity and high selectivity. Long term drift study was undertaken for two consecutive years and significant drift was not observed. Response and recovery time is very crucial in the detection of chronic obstructive pulmonary disease (COPD) and in that front the developed sensor shows extremely fast response and recovery time less than $1 \mathrm{sec}$. Another additional advantage of the developed sensor works safely in the toxic gas environment without any deterioration of its performance, and thus proved it as toxic gas resistant. Stability and selectivity are also good because of the presence of high surface area and thus extensive change in capacitance with the absorption of humidity is observed. A prototype $\mathrm{RH}$ meter has also been developed with digital readout for humidity sensing range as stated above.

\section{Acknowledgements}

This research work is funded by Directorate of Extramural Research \& Intellec- 
tual Property Rights, Defence Research and Development organization, India (No. ERIP/ER/DG-MED \& CoS/990216503/M/01/1620).

\section{Conflicts of Interest}

The authors declare no conflicts of interest regarding the publication of this paper.

\section{References}

[1] Hossein-Babaeiand, F. and Rahbarpour, S. (2014) Alteration of Pore Size Distribution by Sol-Gel Impregnation for Dynamic Range and Sensitivity Adjustment in Kelvin Condensation-Based Humidity Sensors. Sensors and Actuators B: Chemical, 191, 572-578. https://doi.org/10.1016/j.snb.2013.10.032

[2] Tang, Y., Li, Z., Ma, J., Wang, L., Yang, J., Du, B. and Zu, X. (2015) Highly Sensitive Surface Acoustic Wave (SAW) Humidity Sensors Based on Sol-Gel $\mathrm{SiO}_{2}$ Films: Investigations on the Sensing Property and Mechanism. Sensors and Actuators B: Chemical, 215, 283-291. https://doi.org/10.1016/j.snb.2015.03.069

[3] Luo, W., Deng, J., Fu, Q., Zhou, D., Hu, Y., Gong, S. and Zheng, Z. (2015) Nanocrystalline $\mathrm{SiO}_{2}$ Film Prepared by the Aqueous Sol-Gel Method and Its Application as Sensing Films of the Resistance and SAW H2S Sensor. Sensors and Actuators B: Chemical, 217, 119-128. https://doi.org/10.1016/j.snb.2014.10.078

[4] Price, D., Freeman, D., Cleland, J., Kaplan, A. and Cerasoli, F. (2011) Earlier Diagnosis and Earlier Treatment of COPD in Primary Care. Primary Care Respiratory Journal, 20, 15-22. https://doi.org/10.4104/pcrj.2010.00060

[5] Farahani, H., Wagiran, R. and Hamidon, M.N. (2014) Humidity Sensors Principle, Mechanism, and Fabrication Technologies: A Comprehensive Review. Sensors, 14, 7881-7939. https://doi.org/10.3390/s140507881

[6] Laville, C., Deletage, J.Y. and Pellet, C. (2001) Humidity Sensors for a Pulmonary Function Diagnostic Microsystem. Sensors and Actuators B: Chemical, 76, 304-309. https://doi.org/10.1016/S0925-4005(01)00597-4

[7] Nenova, Z., Kozhukharov, S., Nenov, T., Nedev, N. and Machkova, M. (2016) Combined Influence of Titania and Silica Precursors on the Properties of Thin Film Humidity Sensing Elements Prepared via a Sol-Gel Method. Sensors and Actuators B: Chemical, 224, 143-152. https://doi.org/10.1016/j.snb.2015.10.010

[8] Su, P.G., Shiu, W.L. and Tsai, M.S. (2015) Flexible Humidity Sensor Based on Au Nanoparticles/Graphene Oxide/Thiolated Silica Sol-Gel Film. Sensors and Actuators B: Chemical, 216, 467-475. https://doi.org/10.1016/j.snb.2015.04.070

[9] Kozhukharov, S., Nenova, Z., Nenov, T., Nedev, N. and Machkova, M. (2015) Humidity Sensing Elements Based on Cerium Doped Titania-Silica Thin Films Prepared via a Sol-Gel Method. Sensors and Actuators B: Chemical, 210, 676-684. https://doi.org/10.1016/j.snb.2014.12.119

[10] Wales, D.J., Parker, R.M., Gates, J.C., Grossel, M.C. and Smith, P.G. (2013) An Investigation into Relative Humidity Measurement Using an Aluminosilicate Sol-Gel Thin Film as the Active Layer in an Integrated Optical Bragg Grating Refractometer. Sensors and Actuators B: Chemical, 188, 857-866. https://doi.org/10.1016/j.snb.2013.07.089

[11] Tetelin, A., Pellet, C., Laville, C. and Kaoua, G.N. (2003) Fast Response Humidity Sensors for a Medical Microsystem. Sensors and Actuators B: Chemical, 91, 211-218. https://doi.org/10.1016/S0925-4005(03)00090-X 
[12] Chen, Z. and Lu, C. (2005) Humidity Sensors: A Review of Materials and Mechanisms. Sensor Letters, 3, 274-295. https://doi.org/10.1166/sl.2005.045

[13] Varghese, O.K. and Grimes, C.A. (2003) Metal Oxide Nanoarchitectures for Environmental Sensing. Journal of Nanoscience and Nanotechnology, 3, 277-293. https://doi.org/10.1166/jnn.2003.158

[14] Mai, L.H., Hoa, P.M., Binh, N.T., Ha, N. and An, D.K. (2000) Some Investigation Results of the Instability of Humidity Sensors Based on Alumina and Porous Silicon Materials. Sensors and Actuators B: Chemical, 66, 63-65. https://doi.org/10.1016/S0925-4005(99)00458-X

[15] Basu, S., Chatterjee, S., Saha, M., Bandyopadhay, S., Mistry, K.K. and Sengupta, K. (2001) Study of Electrical Characteristics of Porous Alumina Sensors for Detection of low Moisture in Gases. Sensors and Actuators B: Chemical, 79, 182-186. https://doi.org/10.1016/S0925-4005(01)00872-3

[16] Lin, W.D., Liao, C.T., Chang, T.C., Chen, S.H. and Wu, R.J. (2015) Humidity Sensing Properties of Novel Graphene/ $\mathrm{TiO}_{2}$ Composites by Sol-Gel Process. Sensors and Actuators B: Chemical, 209, 555-561. https://doi.org/10.1016/j.snb.2014.12.013

[17] Wang, N., Hsu, C., Zhu, L., Tseng, S. and Hsu, J.P. (2013) Influence of Metal Oxide Nanoparticles Concentration on Their Zeta Potential. Journal of Colloid and Interface Science, 22-28. https://doi.org/10.1016/j.jcis.2013.05.058

[18] Sakulkhu, U., Mahmoudi, M., Maurizi, L., Coullerez, G., Hofmann-Amtenbrink, M., Vries, M. and Hofmann, H. (2015) Significance of Surface Charge and Shell Material of Superparamagnetic Iron Oxide Nanoparticle (SPION) Based Core/Shell Nanoparticles on the Composition of the Protein Corona. Biomaterials Science, 3, 265-278. https://doi.org/10.1039/C4BM00264D

[19] Franks, G.V. and Gan, Y. (2007) Charging Behavior at the Alumina-Water Interface and Implications for Ceramic Processing. Journal of the American Ceramic Society, 90, 3373-3388. https://doi.org/10.1111/j.1551-2916.2007.02013.x

[20] Saha, D., Das, S. and Sengupta, K. (2008) Development of Commercial Nanoporous Trace Moisture Sensor Following Sol-Gel Thin Film Technique. Sensors and Actuators B: Chemical, 128, 383-387. https://doi.org/10.1016/j.snb.2007.06.024

[21] Pandey, M., Mishra, P., Saha, D., Sengupta, K. and Islam, S.S. (2014) Development of Commercial Trace Moisture Sensor: A Detailed Comparative Study on Microstructural and Impedance Measurements of Two Phases of Alumina. Electronic Materials Letters, 10, 357-362. https://doi.org/10.1007/s13391-013-2196-1

[22] Sharma, K. and Islam, S.S. (2016) Optimization of Porous Anodic Alumina Nanostructure for Ultra High Sensitive Humidity Sensor. Sensors and Actuators B: Chemical, 237, 443-451. https://doi.org/10.1016/j.snb.2016.06.041

[23] Daniel, V.V. (1967) Dielectric Relaxation. Academic Press, Cambridge.

[24] https://www.shawmeters.com/

[25] https://www.gemeasurement.com/sites/gemc.dev/files/dew.iq_data_sheet_english_0 $\underline{\text { pdf }}$

[26] http://www.vaisala.com/en/industrialmeasurements/products/humidity/Pages/defa ult.aspx

[27] https://www.tigeroptics.com

[28] Ignjatovic, Z. and Bocko, M.F. (2005) An Interface Circuit for Measuring Capacitance Changes Based upon Capacitance-to-Duty Cycle (CDC) Converter. IEEE Sensors Journal, 5, 403-410. https://doi.org/10.1109/JSEN.2004.841453 